\title{
Categorization of patients with abnormal uterine bleeding according to PALM-COEIN FIGO classification
}

\author{
Arihant Tater ${ }^{1}$, Prakash Jain ${ }^{2 *}$, Kamal Nayan Sharma ${ }^{2}$
}

\begin{abstract}
${ }^{1}$ Department of Obstetrics and Gynecology, Government Medical College, Dungarpur, Rajasthan, India
${ }^{2}$ Department of Obstetrics and Gynecology, RNT Medical College Udaipur, Rajasthan, India
\end{abstract}

Received: 22 September 2019

Accepted: 25 October 2019

\author{
*Correspondence: \\ Dr. Prakash Jain, \\ E-mail: dr.arihanttater@gmail.com
}

Copyright: (c) the author(s), publisher and licensee Medip Academy. This is an open-access article distributed under the terms of the Creative Commons Attribution Non-Commercial License, which permits unrestricted non-commercial use, distribution, and reproduction in any medium, provided the original work is properly cited.

\begin{abstract}
Background: Abnormal uterine bleeding is a common problem of the women in the reproductive age group and leads to the frequent visits of women in hospitals to health care providers. In an effort to create a universally accepted system of nomenclature to describe uterine bleeding abnormalities in reproductive-aged women, an alternative classification system polyp, adenomyosis, leiomyoma, malignancy and hyperplasia, coagulopathy, ovulatory dysfunction, endometrial, iatrogenic, and not yet classified, known by the acronym PALM-COEIN developed.

Methods: It is a retrospective study on 200 patients of abnormal uterine bleeding to categorize them on the basis of PALM-COEIN classification. Patient grouped under these categories after detailed history, examination, investigations and histopathological reports.

Results: Ovulatory dysfunction was the most common cause of AUB in patients presenting to the gynecology outpatient department $(n=60,30 \%)$. It was followed by leiomyoma $(n=48,24 \%)$ and endometrial causes $(n=38,19 \%)$ and were the top three etiologies for AUB respectively. Adenomyosis $(n=26,13 \%)$, not classified $(n=12,6 \%)$, iatrogenic $(n=8,4 \%)$, polyp $(n=4,2 \%)$ and malignancy and coagulopathy each $(n=2,1 \%)$ contributing least to the PALM-COEIN classification as an etiology for AUB.

Conclusions: PALM-COEIN classification is a universally accepted and consistent method of knowing exact etiology following investigations, so the proper treatment can be done for AUB.
\end{abstract}

Keywords: Abnormal uterine bleeding, Adenomyosis, Leiomyoma, Ovulatory dysfunction, PALM-COEIN, Polyp

\section{INTRODUCTION}

Abnormal uterine bleeding (AUB) may be acute or chronic and is defined as bleeding from the uterine corpus that is abnormal in regularity, volume, frequency or duration and occurs in the absence of pregnancy. ${ }^{1,2}$

Abnormal uterine bleeding is a common problem of the women in the reproductive age group and leads to the frequent visits of women in hospitals to health care providers.
In an effort to create a universally accepted system of nomenclature to describe uterine bleeding abnormalities in reproductive-aged women, an alternative classification system polyp, adenomyosis, leiomyoma, malignancy and hyperplasia, coagulopathy, ovulatory dysfunction, endometrial, iatrogenic, and not yet classified, known by the acronym PALM-COEIN, was published in 2011 by the International Federation of Gynecology and Obstetrics and adopted by the American College of Obstetricians and Gynecologists. ${ }^{3}$ 
The PALM-COEIN system classifies uterine bleeding abnormalities by bleeding pattern and etiology. The overarching term AUB is paired descriptive terms to denote bleeding patterns associated with AUB, such as heavy menstrual bleeding (instead of menorrhagia) and intermenstrual bleeding (instead of metrorrhagia). ${ }^{3}$

The term dysfunctional uterine bleeding - often used synonymously with AUB in the literature to indicate AUB for which there was no systemic or locally definable structural cause - is not part of the PALMCOEIN system, and discontinuation of its use is recommended. ${ }^{3}$

By using this system, we can identify the exact etiology of AUB and there can be more than one contributing pathology in symptomatic woman. So exact diagnosis leads to exact treatment.

\section{METHODS}

The present study is a retrospective observational study conducted at the Obstetrics and Gynecology Department of government medical college, Dungarpur from August 2018 to August 2019 for a period of 12 months. During this study, 200 women were enrolled in the present study who met the inclusion criterias.

\section{Inclusion criteria}

- Women between menarche to menopause

- History of unpredictable, irregular menses with excessive bleeding for prolonged duration

- Increased frequency of menses and intermenstrual bleeding for at least 3 months of duration.

\section{Exclusion criteria}

- Women with cervical cause for vaginal bleeding

- Pregnant women with bleeding.

Detailed history of these patients taken including drug history, physical and local examination done, necessary blood investigations like CBC, PT/INR, TSH, S. Prolactin etc. and pelvic ultrasonography was done to rule out any structural abnormalities. Endometrial biopsy and hysterectomy specimens were obtained for histopathology, if needed.

According to the PALM-COEIN classification system, the possible causes were identified and the patients were categorized accordingly. Patients identified with polyp, adenomyosis and leiomyoma after per speculum and per vaginal examination followed by ultrasound were categorized under AUB-P, AUB-A and AUB-L respectively. Bleeding due to endometrial carcinoma diagnosed after either endometrial biopsy or hysterectomy on histopathological examination were included under AUB-M category. Patients taking anticoagulants and with defects of coagulation from younger age were grouped under AUB-C category. Bleeding with unpredictable, irregular timing and variable in amount was suspected to be due to ovulatory dysfunction and categorized under AUB-O. When abnormal menstrual bleeding occurred in cyclical and predictable pattern, typical of ovulatory cycles and no other cause is identified, it was considered as a disorder of endometrium and was placed under AUB-E. Patients presenting with abnormal bleeding due to gonadal steroid hormonal intake during the preceding 3 months or due to the usage of inert or medicated intrauterine device was categorized as iatrogenic and grouped under AUB-I. Women not fitting into any category were put under not yet classified category i.e. AUB-N. ${ }^{4-6}$

\section{Statistical analysis}

Data was analyzed and descriptive statistics were presented as frequencies and percentages.

\section{RESULTS}

In present study, 200 patients were included after fulfilling all the inclusion criterias. All these cases were placed in the nine categories of the PALM-COEIN classification.

Table 1: Age distribution of study population.

\begin{tabular}{|ll|}
\hline A ge group (years) & Overall, $n=200(\%)$ \\
\hline$<20$ years & $6(3)$ \\
\hline $20-29$ years & $14(7)$ \\
\hline $30-39$ years & $78(39)$ \\
\hline $40-49$ years & $92(46)$ \\
\hline$>49$ & $10(5)$ \\
\hline
\end{tabular}

Maximum patients were in the age group of 40-49 years $(\mathrm{n}=92,46 \%)$ (Table 1) with most common presenting complaint of heavy menstrual bleeding $(n=96,48 \%)$ (Table 2).

Table 2: Distribution of study population based on presenting complaint.

\begin{tabular}{|ll|}
\hline Complaint & $\mathrm{n}=200(\%)$ \\
\hline Heavy menstrual bleeding & $96(48)$ \\
\hline Irregular bleeding & $44(22)$ \\
\hline Intermenstrual spotting & $14(7)$ \\
\hline Frequent menses & $46(23)$ \\
\hline
\end{tabular}

After classifying the patients according to PALM-COEIN classification, it was found that Ovulatory dysfunction was the most common cause of AUB in patients presenting to the gynecology outpatient department $(n=60,30 \%)$. It was followed by leiomyoma $(n=48,24 \%)$ and endometrial causes $(n=38,19 \%)$ and were the top three etiologies for AUB respectively. Adenomyosis $(\mathrm{n}=26,13 \%)$, not classified $(\mathrm{n}=12,6 \%)$, iatrogenic $(\mathrm{n}=8$, $4 \%)$, polyp $(n=4,2 \%)$ and malignancy and coagulopathy 
each $(n=2,1 \%)$ contributing least to the PALM-COEIN classification as an etiology for AUB (Table 3).

Table 3: Distribution of study population based on PALM-COEIN classification.

\begin{tabular}{|ll|}
\hline PALM-COEIN & $\mathrm{n}=200(\%)$ \\
\hline Polyp & $4(2)$ \\
\hline Adenomyosis & $26(13)$ \\
\hline Leiomyoma & $48(24)$ \\
\hline Malignancy & $2(1)$ \\
\hline Coagulopathy & $2(1)$ \\
\hline Ovulatory dysfunction & $60(30)$ \\
\hline Endometrial & $38(19)$ \\
\hline Iatrogenic & $8(4)$ \\
\hline Not known & $12(6)$ \\
\hline
\end{tabular}

\section{DISCUSSION}

According to the study done by Qureshi and Yusuf, maximum patients of AUB were classified under leiomyoma category, the number being $25 \%$ followed by ovulatory dysfunction $(24 \%){ }^{7}$ Whereas, in a study done by Gouri et al, maximum number of patients were categorized under ovulatory dysfunction $(27 \%)$ followed by leiomyoma $(24.67 \%)$. Similarly, in the present study also, ovulatory dysfunction $(n=60,30 \%)$ was found to be the most common cause of AUB followed by leiomyoma $(\mathrm{n}=48,24 \%)$. In all above studies ovulatory dysfunction and leiomyoma contributes to the leading cause of AUB.

The present study categorize the patients of AUB according to the PALM-COEIN classification similar to the studies done by Khrouf et al, Munro et al, Madhra et al, Bahamondes and Ali. ${ }^{3,8-10}$

\section{CONCLUSION}

PALM-COEIN classification is a universally accepted and consistent method of knowing exact etiology following investigations, so the proper treatment can be done for AUB. With the advancement of investigation modalities this classification may need to periodic modifications.

Funding: No funding sources Conflict of interest: None declared

Ethical approval: Not required

\section{REFERENCES}

1. ACOG Committee on Practice Bulletins Gynecology. ACOG Practice Bulletin No 108:
Polycystic ovary syndrome. Obstet Gynecol. 2009;114:936-49.

2. Committee on Practice Bulletins-Gynecology. Practice bulletin no. 128: Diagnosis of abnormal uterine bleeding in reproductive-aged women. Obstet Gynecol. 2012;120(1):197-206.

3. Munro MG, Critchley HO, Broder MS, Fraser IS. FIGO working group on menstrual disorders. FIGO classification system (PALM-COEIN) for causes of abnormal uterine bleeding in nongravid women of reproductive age. Int $\mathbf{J}$ Gynaecol Obstet. 2011;113(1):3-13.

4. Barclay L, Murata P. New classification system categorizes causes of abnormal uterine bleeding. Int J Gynecol Obstet. 2011;113:3-13.

5. Abnormal uterine bleeding (AUB) new standardized terminology, definitions, and classification. Available at: http://www.acog.org/-/media/ District VIII/ AbnormalUterineBleeding.pdf. Accessed on $21^{\text {st }}$ December 2015.

6. Abnormal uterine bleeding. The American College of Obstetricians and Gynecologists. FAQ095, December 2012. Available at: http://www.acog.org/ Patients/FAQs/AbnormalUterine-Bleeding. Accessed on $21^{\text {st }}$ December 2015.

7. Qureshi FU, Yususf AW. Distribution of causes of abnormal uterine bleeding using the new FIGO classification system. J Pak Med Assoc 2013: 63:974.

8. Khrouf M, Terras K. Diagnosis and management of formerly called - dysfunctional uterine bleeding\| according to PALM-COEIN FIGO classification and the newguidelines. J Obstet Gynaecol India. 2014;64:388-93.

9. Madhra M, Fraser IS, Munro MG, Critchley HO. Abnormal uterine bleeding: Advantages of formal classification to patients, clinicians and researchers. Acta Obstet Gynecol Scand. 2014;93:619-25.

10. Bahamondes L, Ali M. Recent advances in managing and understanding menstrual disorders. F1000 Prime Rep. 2015;7:33.

Cite this article as: Tater A, Jain P, Sharma KN. Categorization of patients with abnormal uterine bleeding according to PALM-COEIN FIGO classification. Int J Reprod Contracept Obstet Gynecol 2019;8:4783-5. 